\title{
A-kinase anchoring protein 2 is required for calcitonin-mediated invasion of cancer cells
}

\author{
Arvind Thakkar, Ahmed Aljameeli, Shibu Thomas and Girish V Shah
}

Pharmacology, College of Pharmacy, University of Louisiana, Monroe, Louisiana 71291, USA

Correspondence should be addressed to $\mathrm{G} V$ Shah

Email

shah@ulm.edu

\begin{abstract}
Expression of neuropeptide calcitonin (CT) and its receptor (CTR) is frequently elevated in prostate cancers (PCS) and activation of CT-CTR axis in non-invasive PC cells induces an invasive phenotype. Specific, cell-permeable inhibitors of protein kinase A abolish CTRstimulated invasion of PC cells. Since PKA is ubiquitously distributed in cells, the present study examined the mechanism(s) by which CTR-stimulated PKA activity is regulated in time and space. CT reduced cell adhesion but increased invasion of PC cells. Both these actions were abolished by st-Ht31 inhibitory peptide suggesting the involvement of an A-kinase anchoring protein (AKAP) in CT action. Next, we identified the AKAP associated with CT action by the subtraction of potential AKAP candidates using siRNAs. Knock-down of membrane-associated AKAP2, but not other AKAPs, abolished CT-stimulated invasion. Stable knock-down of AKAP2 in PC3-CTR cells remarkably decreased their cell proliferation, invasion, clonogenicity and ability to form orthotopic tumors and distant metastases in nude mice. Re-expression of AKAP2-wt restored these characteristics. Primary PC specimens displayed remarkable upregulation of CTR/AKAP2 expression as compared to benign prostates. Metastatic cancers displayed significantly higher CTR/AKAP2 expression than localized cancers. These results for the first time demonstrate that AKAP2 is expressed in human prostates, its expression is elevated in metastatic prostate cancer, and the knock-down of its expression remarkably decreased tumorigenicity and metastatic ability of prostate cancer cells. AKAP2 may serve as a critical component of CTR-mediated oncogenic actions.
\end{abstract}

\section{Key Words}

- calcitonin receptor-AKAP2prostate cancer-invasion and metastasis

\section{Introduction}

Expression of calcitonin (CT) and its receptor (CTR) is frequently elevated in prostate cancers (PCs). Human prostate CTR belongs to the class B family of G proteincoupled receptors (GPCRs), and is dually coupled to $G_{q}$ and Gs types of heterotrimeric G proteins (Force et al. 1992, Shah et al. 1994, Offermanns et al. 1996, Parthier et al. 2009). In addition to its well-known role in the regulation of serum calcium levels, CTR is crucially involved in the processes associated with development, growth and differentiation (Wookey 2009). Our recent studies suggest that CTR plays a key role in promotion of prostate cancer (PC) metastasis by destabilizing cell-cell junctions, inducing epithelial-to-mesenchymal transition (EMT) and increasing invasion of PC cells

Published by Bioscientifica Ltd.
Endocrine-Related Cancer (2016) 23, 1-14 
(Sabbisetti et al. 2005, Thomas et al. 2006). While the mechanism associated with CTR-mediated junction destabilization remains to be investigated, our results show that CTR-induced invasion can be completely abolished by mPKI, a specific cell-permeable inhibitor of cAMP-dependent protein kinase (PKA; Sabbisetti et al. 2005). These results are consistent with the current evidence that PKA, along with Rho-family GTPases, plays a key role in the regulation of cell-cell adhesion and actin cytoskeleton organization of epithelial cancer cells (Leve et al. 2008).

PKA, a serine threonine kinase, is universally distributed in a cell (Beebe 1994). However, the fidelity of its action is determined by its location and the duration of its activation within a cell. The time and space of PKA action is usually determined by a molecular framework of adapter, anchoring and scaffold proteins that maintain kinases and phosphatases in defined subcellular compartments (Colledge \& Scott 1999). For example, A-kinase anchoring proteins (AKAPs) provide spatial specificity to PKA by tethering the PKA holoenzyme in discrete intracellular environments (Colledge \& Scott 1999, Stratakis \& Cho-Chung 2002, Gold et al. 2006). They may also temporally regulate PKA action by assembling a scaffold of PKA along with its signal terminators such as phosphoprotein phosphatases and cAMP-specific phosphodiesterases. More than 50 AKAPs have been identified. They are highly divergent proteins, but all have a signature PKA regulatory subunit-docking motif (Theurkauf \& Vallee 1982, Wong \& Scott 2004, McConnachie et al. 2006).

To further elucidate the role of PKA in the actions of CTR that decrease cell adhesion and increase invasion of PC cells, we tested the hypothesis that CTR increases invasiveness and metastatic capacity of PC cells by selectively activating AKAP-anchored PKA, and that the AKAP that anchors CTR-activated PKA is localized in the proximity of CTR as well as cell-cell junctions. Our results suggest that CTR-induced actions on cell adhesion and invasion are mediated by PKA that is anchored to AKAP2, a protein localized in the plasma membrane (Gold et al. 2012). Knock-down of AKAP2 or the deletion of its PKAbinding site abolishes CTR-stimulated PC cell invasion as well as orthotopic tumor growth and metastasis of PC xenografts in nude mice.

\section{Material and methods}

\section{Animals}

Male balb/c nu/nu mice (6-8 weeks old) were purchased from Harlan (Madison, WI, USA), and housed two per cage in microisolator units under 70\% humidity and temperature-controlled conditions. The animals were fed $a d$ lib on a standard sterilizable laboratory diet (Teklad Lab chow, Harlan Teklad) and quarantined for 1 week prior to their use in the study.

\section{Surgical orthotopic implantation}

All animal procedures were conducted in accordance with the principles and procedures outlined by the NIH and Institutional Animal Care and Use Committee at University of Louisiana at Monroe. The Surgical orthotopic implantation was performed under Ketamine/Xylazine anesthesia as previously described (Chien et al. 1999, Shah et al. 2008, Shah et al. 2009a). In brief, tumor cell suspensions $\left(1 \times 10^{6}\right.$ cells $/ 20 \mu \mathrm{l}$ ) were injected into the dorsal prostate, the mice were maintained on the laboratory diet ad libitum for up to 60 days, and were regularly monitored for tumor growth/ metastasis with fluorography using Kodak $4000 \mathrm{MM}$ imaging station (Eastman Kodak Company, Rochester, NY, USA) (Thomas et al. 2006).

\section{Cell culture}

PC cell lines LNCaP, PC-3 and DU-154 were obtained from ATCC (Manassas, VA, USA), and maintained as recommended by ATCC. All cell lines were cultured under previously described culture conditions (Shah et al. 2009b). PC-3CTR cell line was generated by stable transfection of pcDNA3.1 containing full-length CTR cDNA cloned from LNCaP cells as described previously (Shah et al. 2009b). The cell lines and modified sublines were used only up to passage 12. Primary cell lines were used within 6 months of their purchase. PC-3 and PC-CTR cells were used to generate $\mathrm{AKAP} 2_{\mathrm{KD}}, \mathrm{AKAP2}$-reexp and PKAP2 $\triangle \mathrm{PKA}$ sublines. Therefore, PC-3 and PC-3CTR cell lines were authenticated by STR profiling at the John Hopkins University Medical Center. The results demonstrating their authenticity are provided as a Shah Supp Fig. 1, see section on supplementary data given at the end of this article. The sublines were used immediately after the stable transfection.

\section{Generation of AKAP2 ${ }^{\mathrm{KD}}$ cell lines}

PC-3CTR cells were used for this study because they are PC-3-derived, but co-express CT and CTR and are suitable to study modulation of CTR action in response to changes/mutations in AKAP2 molecule (Chien et al. 2001). Endogenous AKAP2 expression of PC-3CTR cells was silenced by stable expression of constitutive AKAP2

Published by Bioscientifica Ltd 
shRNA expression vector (pSuper.neo system; shRNA duplex- 5'- GCCAUAAAAUGAAUGGCXGUTT-3' corresponding 3279-3295 bp of human AKAP2 transcript). Since the constitutive presence of AKAP- 2 shRNA in PC3CTR cells could interfere with the re-expression of AKAP2-wt or its $\triangle$ PKA mutant (where the $\triangle$ PKA-binding domain of AKAP2 (aa 566-579) was deleted), we generated the cDNA expression vectors refractory to AKAP2 RNAi by introducing a silent mutation in RNAi target sequence in the AKAP2-wt or AKAP2- $\triangle \mathrm{PKA}$ transgenes. The cells were then transfected with either AKAP2-wt-zeocin or AKAP2$\triangle$ PKA-zeocin transgenes. All AKAP2 plasmids were HA-tagged. The colonies of stable transfectants were screened for the knock-down of AKAP2 as well as its re-expression with AKAP2-wt and AKAP2- $\Delta$ PKA constructs by western blotting. The stable clones expressing each vector were pooled and maintained in a medium containing G418 \pm zeocin.

\section{Cell adhesion assay}

Twenty-four-well plates were coated with PBS, Laminin-1 or Fibronectin at $4{ }^{\circ} \mathrm{C}$ overnight. The plates were then chilled and seeded with $10^{5}$ cells/well. The cells were then incubated for $60 \mathrm{~min}$ in the presence/absence of agents. After washing, the cells were fixed in 4\% paraformaldehyde and stained with Crystal Violet for $10 \mathrm{~min}$. The plates were then dried, and adherent cells were solubilized in $2 \%$ SDS and read for optical density at $550 \mathrm{~nm}$.

\section{In vitro invasion assay}

Invasion experiments were conducted in 24-well, two compartmented, Matrigel invasion chambers (Becton Dickinson, Bedford, MA, USA) as previously described (Sabbisetti et al. 2005).

Growth Correction Since CT also induces proliferation of PC cell lines, we determined the factor to correct for possible proliferation of cells that may have migrated in early phase of $24-\mathrm{h}$ incubation period. Then, $25 \times$ $10^{4}$ cells were plated at hourly intervals in six-well dishes and cultured for 1-24 h. Mean percent increase in cell number in each well was determined. This correction was applied to the results of invasion assays.

\section{Orthotopic tumor growth and metastasis}

Stable expression of red fluorescence protein To detect micrometastases of implanted tumor cells in mice, we stably transfected the cell lines with DsRed-MCherryHyg-N1, a mammalian expression vector that encodes DsRed-MCherry, a derivative of red fluorescent protein (Clontech, Palo Alto, CA, USA). Hygromycin-resistant colonies were selected, and observed over a period of 4 weeks. All cell lines expressed strong red fluorescence at a steady level over the duration of the observation period. The cells were then used for orthotopic implantation in $\mathrm{nu} / \mathrm{nu}$ mice. The mice were observed for tumor growth over a period of $6-8$ weeks.

Histology At necropsy, primary tumors and several organs were harvested and weighed. Wet sections of organs were examined for the presence of RFP. Fluorescent images of tumor cells were acquired with a charge-coupled device Retiga 2000 RT digital camera connected to a Nikon Optiphot-2 (Nikon, Tokyo, Japan). The remaining tissues were fixed in neutral buffered formalin and embedded in paraffin. The $5-\mu \mathrm{m}$ thick sections were processed for $\mathrm{H} \& \mathrm{E}$ staining.

\section{AKAP, ZO-1 and E-cadherin immunocytochemistry}

Fixed PC cells were immunolabeled with primary antibodies (mouse Anti-AKAP-KL, BD Transduction Laboratories; rabbit Anti-ZO-1, Invitrogen; goat anti-E-Cadherin, R\&D systems) for overnight at $4{ }^{\circ} \mathrm{C}$. The appropriate secondary antibodies conjugated with fluorophores FITC, TRITC or Alexa Fluor 350 was applied. After washes, the slides were observed under Nikon Optiphot-2 microscope equipped for epifluorescence. The images were captured with Retiga 1300 camera connected to an iMac computer loaded with the iVision image analysis program (Biovision Technologies, Exton, PA, USA). All antibodies were characterized for specificity and cross-reactivity as described in Figs S1-S3, see section on supplementary data given at the end of this article.

\section{CTR, AKAP2 IHC of PC specimens}

Monoclonal CTR antibody was purchased from Acris (San Diego, CA, USA). Characterization of CTR and AKAP-KL antibodies is presented in Supplementary Figs S1-S3, see section on supplementary data given at the end of this article. Specimens of benign prostatic hyperplasia $(\mathrm{BPH})$, localized and metastatic PCs were purchased from commercial sources (PR955; US Biomax, Rockville, MD, USA and TRP- 1 of NCI). The cohorts included BPH $(n=16)$; localized PC $(n=30)$ and metastatic PC $(n=37)$. The slides were deparaffinized, and following antigen retrieval, immunohistochemistry was performed as described

Published by Bioscientifica Ltd. 
previously (Shah et al. 2008). Incubations with anti-CTR (Acris) or AKAP-KL monoclonal antibody were followed by TRITC-conjugated secondary antiserum. The slides were then counterstained with DAPI and assessed for immunostaining. Six randomly selected images of every specimen were captured with a Retiga 1300 camera connected to a Nikon Optiphot-2 microscope equipped for epifluorescence. Immunostaining was scored by two individuals independently using the established methods (Jackel et al. 2001), and the mean reading was taken. Number of AKAP2-positive cells (red) and total cells (stained blue) per $400 \times$ field were counted; and staining intensity was assigned an arbitrary value, on a scale of $0-3$ as follows: $(-)=0,( \pm)=0.5,(+)=1,(++)=2,(+++)=3$.

An IHC index for each sample was calculated by multiplying staining intensity with the percentage of positive cells. The results were graded from 0 (negative) to 300 (all cells display strong staining intensity). Reproducibility of the analysis was verified by rescoring of randomly chosen slides. Duplicate readings gave similar results.

\section{Co-immunoprecipitation}

Serum-starved PC-3-CTR cells $\left(2 \times 10^{6} / 100 \mathrm{~mm}\right.$ dish) were washed, and lysed in immunoprecipitation buffer as previously described (von Zastrow \& Kobilka 1994). In brief, CTR-FLAG was immunoprecipitated from equal lysate proteins per sample ( $\sim 2.5-4 \mathrm{mg}$ protein per lysate) with anti-FLAG EZ-view beads (Sigma). The CTR-FLAG immunoprecipitates were eluted with FLAG peptide, fractionated on a polyacryl amide gel by electrophoresis and transferred on to PVDF blot. The blot was probed for ZO-1, AKAP2 and E-cadherin by immunoblotting. Preimmune lysate was used as input control.

\section{Statistical analysis}

The results were statistically analyzed by one-way ANOVA or as described in the results section. The significance was derived from Newman-Keuls test. The difference was considered statistically significant when $P<0.05$.

\section{Results}

\section{CT reduces cell adhesion and increases invasion of prostate cancer cells: attenuation of its action by stearated Ht-31 peptide}

Earlier studies from this laboratory have shown that CT significantly increased invasion of PC cells, and mPKI, a cell-permeable specific inhibitor of PKA, almost abolished this effect (Sabbisetti et al. 2005). To investigate whether PKA that mediates the action of CT on cell adhesion and invasion is anchored by an AKAP, we examined the effects of CT in the presence/absence of $\mathrm{Ht}-31$, an anchoring inhibitor peptide that occupies PKAbinding site on AKAP molecules (Jarnaess et al. 2008). The peptide does not interfere with the PKA activity, but uncouples the bound PKA from an AKAP molecule (Vijayaraghavan et al. 1997, Gold et al. 2006).

Figure 1 shows that CT $(50 \mathrm{nM})$ decreased the adhesion of PC-3CTR cells on plastic (Fig. 1A1 and A2), laminin (Fig. 1B1 and B2) and fibronectin (Fig. 1C1 and C2). However, the effect of CT on cell adhesion on laminin was almost half of that on plastic or fibronectin. These results are consistent with our earlier observations and suggest that CT interacts with laminin-activated integrins (Thomas et al. 2007). When treated with Ht-31Pro (the control peptide for Ht-31, $50 \mu \mathrm{M}$ ), the peptide did not affect cell adhesion of either control cells or CT-treated cells (Fig. 1A3 and A4) on plastic; laminin (Fig. 1B3 and B4) as well as fibronectin (Fig. 1C3 and C4). Ht-31 $(50 \mu \mathrm{M})$ did not alter the adhesion of control cells on all surfaces, but remarkably reversed CT-induced decline of cell adhesion (Fig. 1A5 and A6 on plastic; Fig. 1B5 and B6 on laminin; and Fig. 1C5 and C6 for fibronectin). Figure 1C shows quantitative analysis of cell adhesion. The results demonstrate that CT significantly decreased the adherence of cells on plastic and fibronectin, and this action was almost abolished or markedly reduced by Ht-31.

In contrast, CT significantly increased the invasion of PC3-CTR cells (Fig. 1D). Ht-31Pro did not affect the invasion of either vehicle-treated or CT-treated cells. Ht-31 did not alter the invasion of vehicle-treated PC-3CTR cells, but significantly decreased CT-stimulated invasion (Fig. 1E). These results suggest that the action of CT on cell adhesion and invasion is mediated by the PKA that is anchored to an AKAP molecule. AKAP plays an important role in CT action by providing spatio-temporal specificity.

\section{Identification of an AKAP associated with CTR actions}

Since more than 50 AKAPs have been reported, we attempted to identify an AKAP associated with CTRmediated invasion. Because CTR is a membrane receptor, we first examined AKAPs that have been localized to the plasma membrane such as type $2,5,8,11$, and 12 .

Knock-down of membrane AKAPs and CTR-stimulated invasion To identify the AKAP associated with

Published by Bioscientifica Ltd. 
A
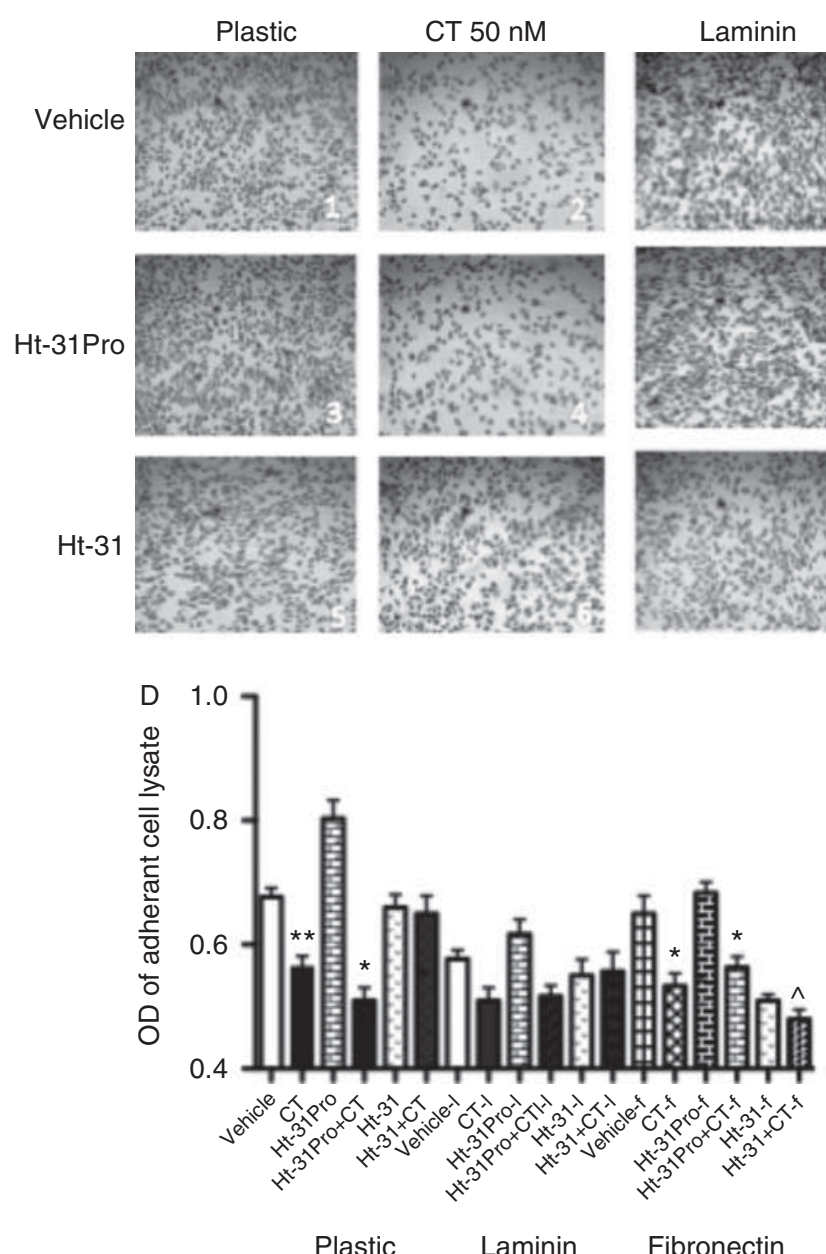

B
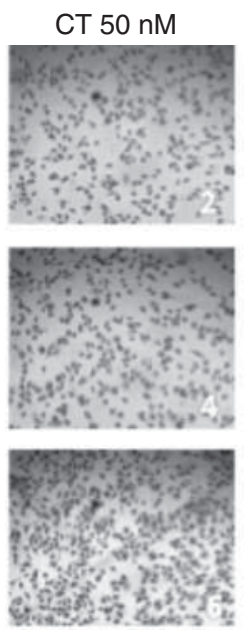
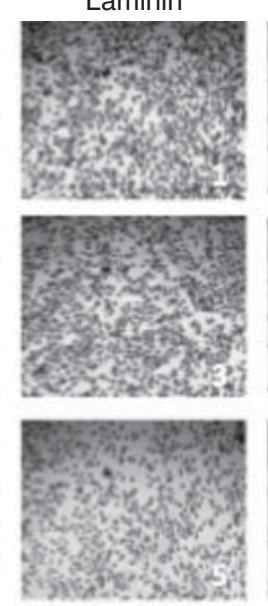
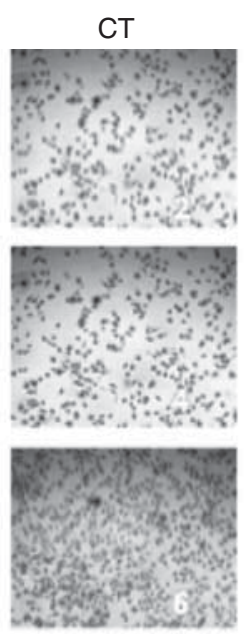

C
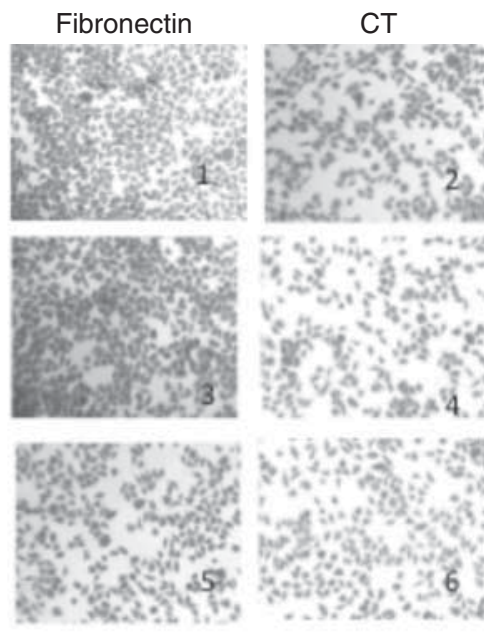

E

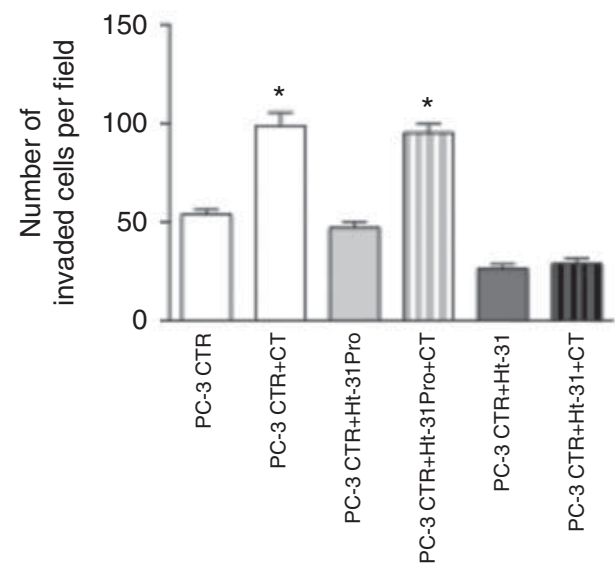

Figure 1

Role of AKAP in the actions of CT on cell adhesion and invasion of prostate cancer cells. Representative photomicrographs of PC-3CTR cell adhesion to plastic (A and B) laminin $(10 \mu \mathrm{g} / \mathrm{ml})$ or (C) fibronectin $(10 \mathrm{mg} / \mathrm{ml})$; and its modulation by $\mathrm{CT}(50 \mathrm{nM})$ (in the presence/absence of $50 \mu \mathrm{M} \mathrm{st}-\mathrm{Ht}-31$ Pro and $50 \mu \mathrm{M}$ stHt-31). Cells were allowed to adhere for $30 \mathrm{~min}$ as indicated. (D) Colorimetric analysis of adherent cell lysates of four independent experiments similar to that depicted in Fig. 1A. The results are expressed as mean \pm s.E.M. $P<0.001$ ( ${ }^{* *} \mathrm{CT}$ vs. st $+\mathrm{Ht} 31 ;{ }^{*} \mathrm{Ht} 31 \mathrm{Pro}$ vs $\mathrm{Ht} 31+\mathrm{CT} ;{ }^{\wedge} \mathrm{CT}$ vs
$\mathrm{Ht}-31+\mathrm{CT}-\mathrm{f}$; one way ANOVA and Newman-Keuls test). (E) Effect of CT on invasion of prostate cancer cells. PC-3CTR cells were added to the upper insert of invasion chambers along with/without $50 \mathrm{nM} \mathrm{CT}$ (in the presence/absence of $50 \mu \mathrm{M}$ st-Ht-31Pro and $50 \mu \mathrm{M}$ st-Ht-31), and cells that passed through the Matrigel barrier were counted after $48 \mathrm{~h}$. The results are expressed as mean number of invaded cells per $400 \times$ field \pm s.E.M. for $n=6$. ${ }^{\star} P<0.05$ (PC-3CTR vs PC-3CTR + CT; PC-3CTR $+\mathrm{Ht}-31$ Pro vs PC-3CTR + $\mathrm{Ht}-31$ Pro $+\mathrm{CT}$; one way ANOVA and Newman-Keuls test).

of PC-3CTR cells to a variable extent. CT could still increase the invasion of cells receiving siRNAs for AKAP 5, 8, 11, and 12 (Fig. 2B). But, AKAP2 siRNA caused a maximal decrease in basal invasion of PC-3CTR cells; and more importantly, CT could not stimulate the invasion of AKAP2 $\mathrm{k} / \mathrm{d}$ cells, suggesting that AKAP2 may be associated with the stimulatory action of CT on invasion of PC cells (Fig. 2C) (Dong et al. 1998).

Because Ht-31 acts on all AKAPs whereas AKAP2 siRNA should be specific for AKAP2 alone, we compared the effect 
A

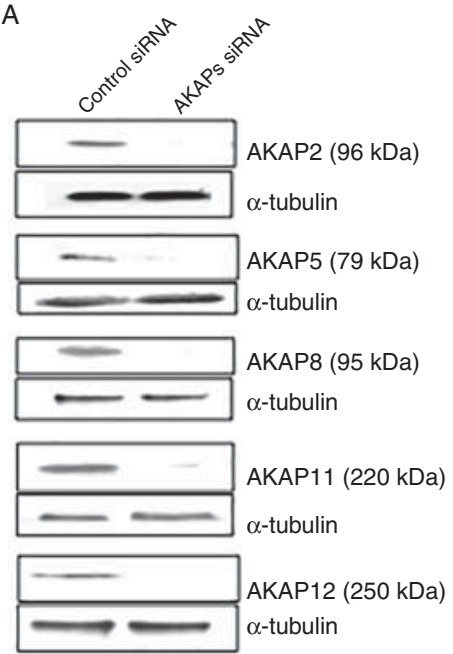

C

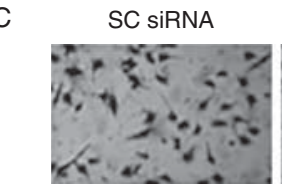

SC siRNA+CT
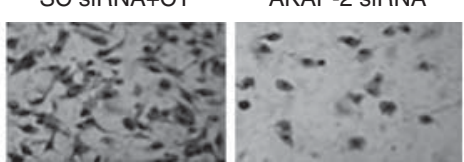

G
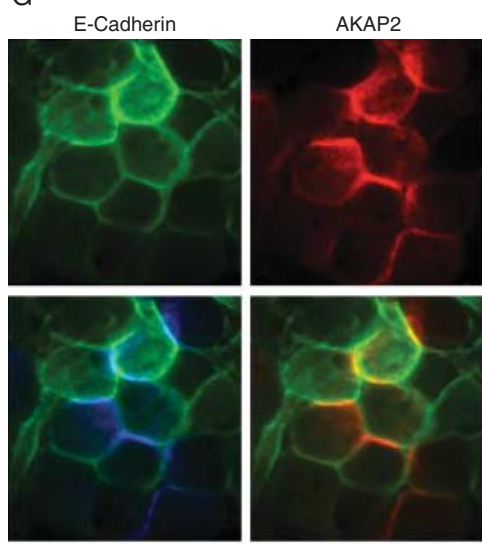

ZO-1+E-CAD

B
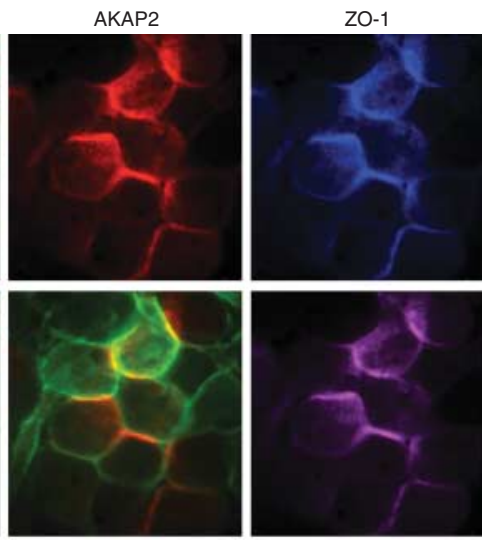

AKAP2+E-CAD

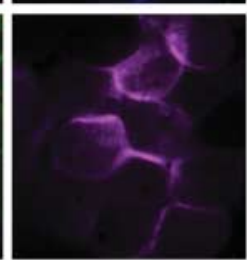

ZO-1+AKAP2

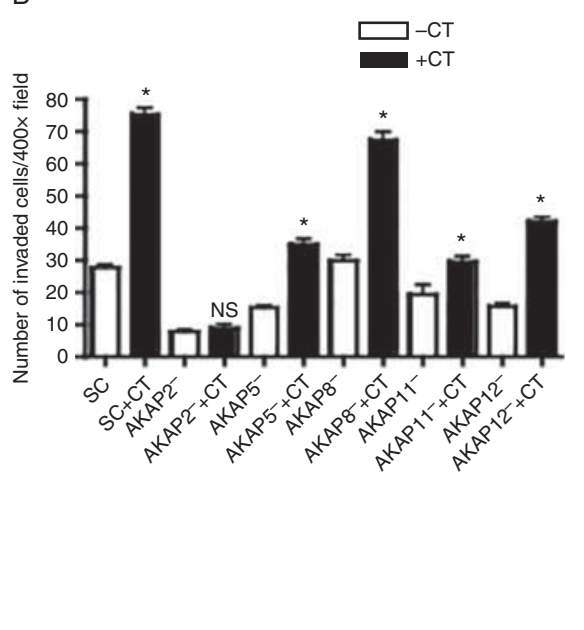

AKAP-2 siRNA+CT

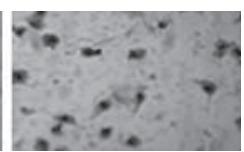

$\mathrm{H}$

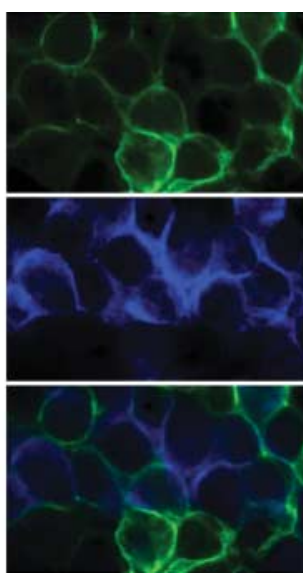

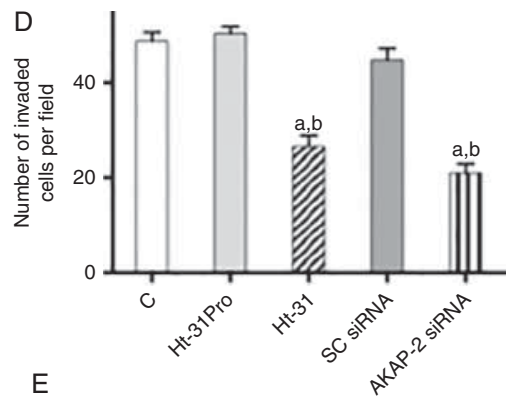

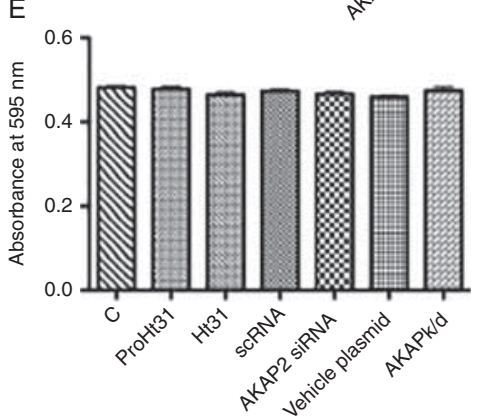

F

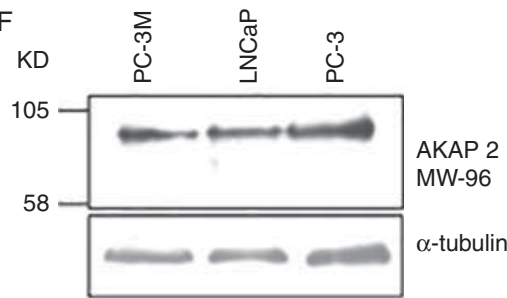

E-Cadherin

Co-precipitation with CTR

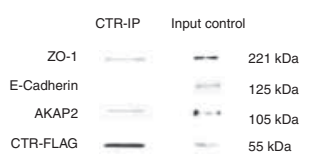

Merge

\section{Figure 2}

Identification of AKAP associated with the action of CT on PC-3CTR cell invasion. (A) Immunoblotting of PC-3CTR lysates for the appropriate AKAP. The cells were lysed $72 \mathrm{~h}$ after transfection with appropriate scrambled or siRNA. (B) Invasion of PC-3CTR cells $72 \mathrm{~h}$ after transfection with either scrambled or AKAP siRNA as indicated. Each cell well was treated with/without $50 \mathrm{nM} \mathrm{CT}$. The results are expressed as mean number of invaded cells per $400 \times$ field \pm S.E.M for $n=6$. $* P<0.01$ (control vs CT-treated) (one-way ANOVA and Newman-Keuls test). (C) Representative photomicrographs of invaded cells at the end of the treatment as indicated. (D) PC-3CTR cells transfected with either scrambled or siRNA or untreated PC-3CTR cells were added to the upper insert of invasion chambers and treated with/without $50 \mathrm{nM} \mathrm{CT}$ (and with st-Ht-31Pro or st-Ht-31 as indicated), and cells that passed through the Matrigel barrier were counted after $48 \mathrm{~h}$. The results are expressed as mean number of invaded cells per $400 \times$ field \pm s.E.M. for $n=6$. $P<0.01$ ( ${ }^{\mathrm{a}}$ vs. $\mathrm{C}^{\mathrm{b}}{ }^{\mathrm{b}}$ vs Ht-31Pro; one way ANOVA and Newman-Keuls test) (E) PC -3CTR cells were plated in 96-well plate and transfected with either scrambled or siRNA or treated with $\mathrm{Ht}-31$ (or control peptide). After $48 \mathrm{~h}$ of incubation, the viability of attached cells was determined. The results are expressed as mean \pm s.E.M. of $\mathrm{OD}_{560}$. (F) Presence of AKAP2 immunoreactivity in cell lysates of LNCaP, PC-3 and PC-3M cells. (G) Localization of AKAP2 in PC-3CTR cells. PC-3CTR cells were plated on coverslip and subjected to AKAP2, ZO-1, E-cadherin ICC as described in the methods sections. $400 \times$ micrographs presenting AKAP2 immunostaining (TRITC-red), ZO-1 immunostaining (Alexa Fluor 350-Blue) and E-cadherin (FITC-green). (H) Double immunostaining of ZO-1 (Alexa Fluor 350-Blue) and E-cadherin (FITC-Green). No colocalization was observed. (I) A western blot showing the co-precipitation of AKAP2 and ZO-1, but not E-cadherin, with CTR. The column on the right shows input control (PC3-CTR cell lysate prior to immunoprecipitation), which shows all four proteins but in much smaller amounts. 
of AKAP2 siRNA with Ht-31 on CT action. The results of Fig. 2D demonstrate that AKAP2 siRNA was at least as potent as Ht-31 in attenuating CT-stimulated invasion, raising a possibility that AKAP2 alone may be associated CTR action that stimulates the invasion of PC cells.
To ascertain that the inhibitory invasion of Ht-31 and AKAP2 siRNA is not due to their cytotoxic effects, we treated the cells with the agents under the experimental conditions of Fig. 2D, and examined their cell viability by MTT assay. The results of Fig. 2E suggest that neither our
A
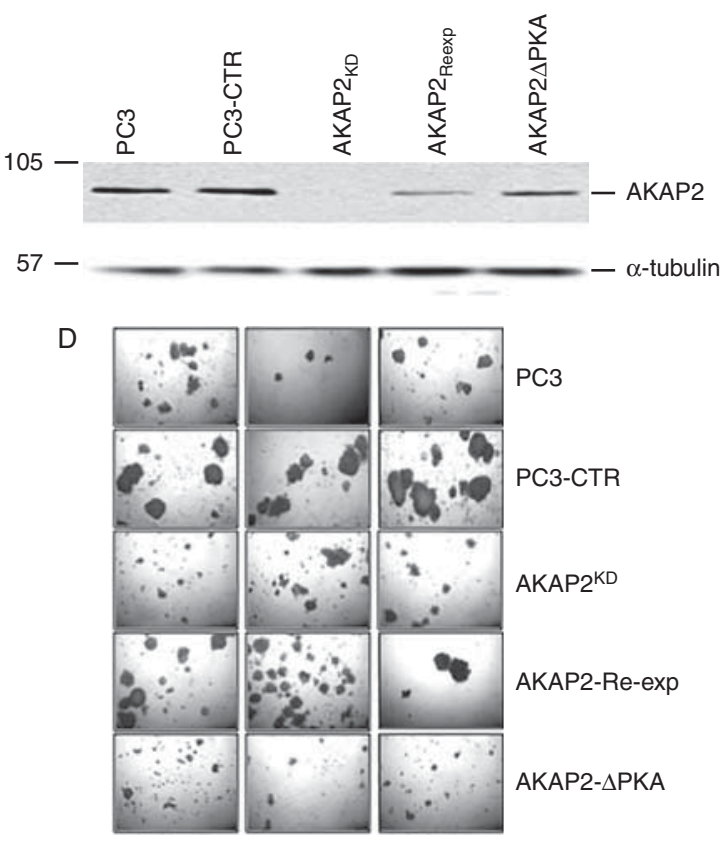

$\mathrm{E}$

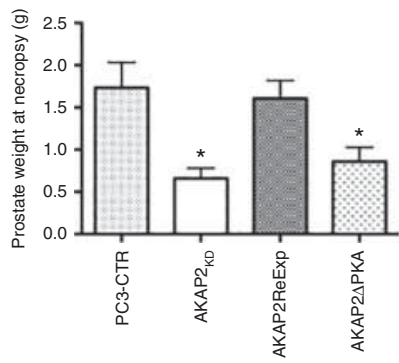

B

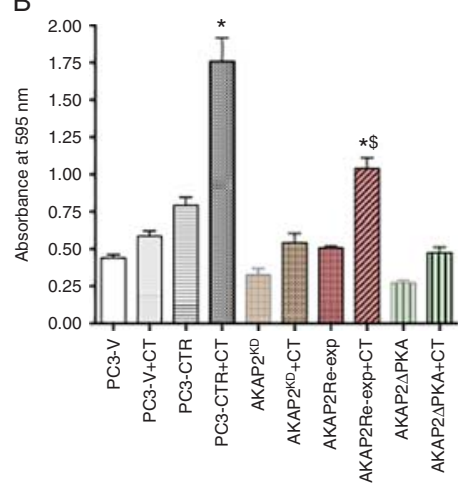

$\mathrm{F}$
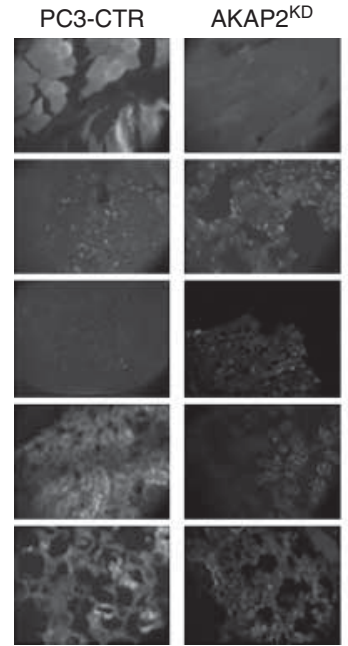

C

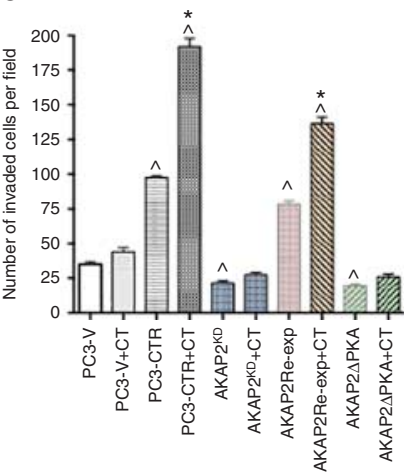

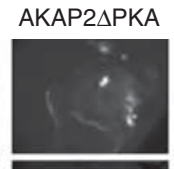
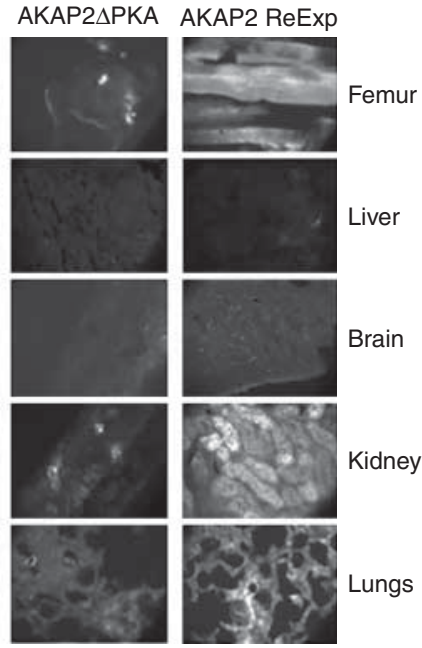

without $C T$ for each cell line); ${ }^{\wedge} P<0.05$ (each cell line vs $P C-3$ ) (one-way ANOVA and Newman-Keuls test). (D) Role of AKAP2 in clonogenic growth of PC cell lines. Representative photomicrographs of colonies formed by various sublines as indicated. PC3, PC-3CTR or AKAP2 sublines (as indicated) were grown on soft agar for 2 weeks as described in the methods section. The cells grown on soft agar were then stained with crystal violet and photographed. Each group had at least four replicates. (E) Role of AKAP2 in prostate cancer xenografts growth in nude mice. PC- 3, PC-3CTR and AKAPsublines (as indicated) were stably transfected with DsRed-MCherry-Hyg-N1 (Clontech). Hygromycin resistant colonies that expressed strong red fluorescence at a steady level over the observation period were selected, and used for orthotopic implantation. Animals were sacrificed 8 weeks after implantation, and prostate tumors were weighed. $* P<0.01$ (compared to PC-3CTR); one-way ANOVA and Newman-Keuls test. (F) The indicated organs from the mice described in Fig. $3 E$ were removed and observed directly under fluorescent microscope. The images were captured at $100 \times$ magnification.

Published by Bioscientifica Ltd

(C) 2016 Society for Endocrinology Printed in Great Britain 
experimental procedures nor the AKAP2 knock-down affected the viability of PC3-CTR cells.

\section{Expression of AKAP2 in PC cell lines}

We next examined the presence of AKAP2 immunoreactivity in $\mathrm{LNCaP}, \mathrm{PC}-3 \mathrm{M}$ and $\mathrm{PC}-3$ cell lines by western blotting. The results of Fig. $2 \mathrm{~F}$ demonstrate the presence of AKAP2 in all three PC cell lines.

\section{AKAP2 is localized on plasma membrane of PC cells}

Available evidence indicates that AKAP2 is localized to the plasma membranes of mouse kidney and lung cells (Dong et al. 1998). However, its presence or the subcellular localization in prostate cells has not been reported. We localized AKAP2 to the cell-cell junctions of PC3-CTR cells by triple immunocytochemistry using zonula occludens-1 (ZO-1), a tight junction marker; and E-cadherin, an adherent junctions marker (Fig. 2G) (Cereijido et al. 1993, Lewis et al. 1994, Rajasekaran et al. 2004). AKAP2ZO-1 co-localization was observed in $98 \%$ of cells. In contrast, AKAP2-E-Cadherin co-localization was much less frequent $(\sim 26 \%)$. Moreover, the cells that showed co-localization of AKAP2 with E-cadherin also showed co-localization of ZO-1 with E-cadherin. Since ZO-1 and E-cadherin are distinctly localized in tight and adherens junctions respectively (Ebnet 2008), it is very likely that AKAP2-E-cadherin co-localization seen in small number of cells in Fig. 2G may have been due to inability of our microscope to separate tight junctions from adherens junctions in those specific areas (Fig. 2H). Nevertheless, the results demonstrate that $\mathrm{AKAP} 2$ is localized in the plasma membrane of PC3-CTR cells in close proximity of cell-cell junctions.

To verify the localization of AKAP2 in tight junctions and examine its relationship with CTR, we examined the presence of AKAP2 and/or ZO-1 in CTR immunoprecipitates. The results of Fig. 2I demonstrate that AKAP2 and ZO-1 co-precipitated with CTR. However, E-cadherin was undetectable. These results support our ICC data and suggest a close association between CTR, ZO-1 and AKAP2.

\section{Characterization of AKAP2-modified PC-3CTR cell lines}

To examine the role of AKAP2 in prostate tumor growth and metastasis, we generated multiple PC-3CTR sublines with modulated AKAP2 expression (Fig. 3A) such as silencing of AKAP2 (AKAP2 $\mathrm{KD})$, and its re-expression with either AKAP2-wt or AKAP2- $\triangle$ PKA. The presence of AKAP2 protein after these modifications was confirmed by western blot analysis of their cell lysates: PC-3 and PC-3CTR cells displayed AKAP2 immunoreactivity (Lanes 1,2 of Fig. 3A). AKAP $\mathrm{KD}_{\mathrm{D}}$ cells lacked AKAP2 immunoreactivity (Lane 3 of Fig. 3A), but it reappeared in AKAP2Re-exp (re-expression) and AKAP2- $\Delta$ PKA cells (Lanes 4, 5 of Fig. 3A).

\section{Cell proliferation of AKAP2-modulated PC cell lines}

As expected, CT did not alter the proliferation of PC-3V cells (lack endogenous CTR) (Chien et al. 2001). However, PC3-CTR cells displayed higher rate of proliferation; and CT significantly increased their rate of proliferation (Fig. 3B). The knock-down of AKAP2 by itself remarkably reduced the rate of cell proliferation of PC-3CTR cells, and CT-stimulated increase was also remarkably attenuated. Re-expression of AKAP2 restored the baseline rate of cell proliferation, and partially restored CT response. However, the re-expression of AKAP2 $\triangle$ PKA did not restore the baseline proliferation rate and only partially restored CT-stimulated proliferation. These results suggest that AKAP2-PKA complex may mediate proliferative actions of CT on PC-3CTR cells only partially, and AKAP2-independent mechanisms may also be involved.

\section{Invasion}

CT significantly increased invasion of PC-3CTR cells (Fig. 3C). AKAP $2_{\mathrm{KD}}$ cells were remarkably less invasive; and $\mathrm{CT}$ could not increase the invasion further. Invasion of AKAP2-reexpresed cells was comparable to PC3-CTR cells; and CT increased it further. However, the baseline as

Table 1 Organ weights

\begin{tabular}{|c|c|c|c|c|}
\hline Organs & PC-3-CTR & AKAP2 $_{K D}$ & $\begin{array}{l}\text { AKAP2 } \\
\text { Re-exp. }\end{array}$ & $\begin{array}{c}\text { AKAP2 } \Delta \\
\text { PKA }\end{array}$ \\
\hline $\begin{array}{l}\text { Seminal } \\
\text { vesicles }\end{array}$ & $0.34 \pm 0.12$ & $0.03 \pm 0.02$ & $0.23 \pm 0.11$ & $0.06 \pm 0.07$ \\
\hline $\begin{array}{l}\text { Testes } \\
\text { Lymph } \\
\text { nodes }\end{array}$ & $0.36 \pm 0.13$ & $0.04 \pm 0.02$ & $0.25 \pm 0.12$ & $\begin{array}{l}0.06 \pm 0.06 \\
0.14 \pm 0.10\end{array}$ \\
\hline Mesentery & $0.20 \pm 0.12$ & $0.05 \pm 0.04$ & $0.31 \pm 0.14$ & $0.03 \pm 0.03$ \\
\hline $\begin{array}{l}\text { Femur } \\
\text { Stomach }\end{array}$ & $0.50 \pm 0.16$ & $0.06 \pm 0.05$ & $\begin{array}{l}0.38 \pm 0.17 \\
0.45 \pm 0.11\end{array}$ & $0.07 \pm 0.05$ \\
\hline Kidneys & $0.28 \pm 0.066$ & $0.05 \pm 0.04$ & $0.33 \pm 0.13$ & $0.07 \pm 0.10$ \\
\hline Lungs & $0.48 \pm 0.16$ & $0.07 \pm 0.05$ & $0.45 \pm 0.17$ & $0.06 \pm 0.05$ \\
\hline Heart & $0.41 \pm 0.15$ & $0.06 \pm 0.06$ & $0.34 \pm 0.14$ & $0.05 \pm 0.06$ \\
\hline Brain & $0.30 \pm 0.14$ & $0.06 \pm 0.06$ & $0.24 \pm 0.10$ & $0.05 \pm 0.05$ \\
\hline Liver & $0.37 \pm 0.15$ & $0.04 \pm 0.03$ & $0.37 \pm 0.12$ & $0.06 \pm 0.07$ \\
\hline
\end{tabular}

Published by Bioscientifica Ltd. 
Table 2 Frequency of micrometastases in host organs

\begin{tabular}{|c|c|c|c|c|c|}
\hline Organs & PC-3CTR & AKAP $_{K D}$ & $\begin{array}{c}\text { AKAP2- } \\
\text { DPKA }\end{array}$ & AKAP2 $2_{\text {REEXP }}$ & $\begin{array}{l}\text { Number of } \\
\text { animals (n) }\end{array}$ \\
\hline $\begin{array}{l}\text { Seminal } \\
\text { vesicles }\end{array}$ & 6 & 0 & 0 & 6 & 6 \\
\hline $\begin{array}{l}\text { Lymph } \\
\text { nodes }\end{array}$ & 6 & 1 & 1 & 6 & 6 \\
\hline Femur & 4 & 0 & 0 & 3 & 6 \\
\hline Lungs & 3 & 0 & 0 & 3 & 6 \\
\hline Liver & 3 & 0 & 0 & 3 & 6 \\
\hline Kidneys & 3 & 0 & 0 & 3 & 6 \\
\hline Brain & 1 & 0 & 0 & 1 & 6 \\
\hline
\end{tabular}

well as CT-stimulated invasion of AKAP2 $\triangle$ PKA cells was comparable to that of $\mathrm{AKAP} 2^{\mathrm{KD}}$ cells. These results demonstrate that AKAP2 plays an important role in the invasion of PC-3CTR cells by tethering the PKA activated by CTR; and CTR-stimulated PKA-induced phosphorylation may play a key role in CT-stimulated invasion of these cells.

\section{Clonogenic growth}

Cancer cells, but not normal cells, can grow in the absence of substratum or display anchorage-independent growth. Growth in soft agar is reflective of their tumorigenicity and invasiveness. We examined the role of CTR and AKAP2 in tumorigenicity/invasiveness of PC-3 cells by their ability to form colonies on soft agar. The results of Fig. 3D demonstrate that the expression of CTR alone in PC-3 cells caused a dramatic increase in their ability to form colonies. These results are consistent with our earlier report (Thomas et al. 2006). AKAP2 ${ }^{\mathrm{KD}}$ cells displayed greatly reduced ability to grow or form colonies in soft agar. AKAP2-wt re-expression restored this ability, but AKAP2 $\triangle$ PKA re-expression did not. These results confirm that AKAP2-PKA complex plays a key role in tumorigenicity and invasiveness of PC cells.

\section{Role of AKAP2 in tumorigenicity and metastatic capacity of PC-3CTR cells}

We next examined the role of AKAP2 on tumor growth and metastasis of PC-3 cells in orthotopic nu/nu mouse model. We have already shown that the enforced CTR expression significantly increases the ability of PC-3 cells to form orthotopic tumors as well as distant metastases (Thomas et al. 2006, Shah et al. 2008). In this study, we examined the ability of AKAP2 to modulate tumor growth and metastatic capacity of PC-3CTR cells. AKAP2 $2_{\mathrm{KD}}$ cells displayed significantly lesser ability to form orthotopic tumors as assessed by the wet weight of the prostate at necropsy (Fig. 3E). However, the re-expression of AKAP2-wt completely restored this ability, while the re-expression of AKAP2 $\triangle$ PKA did not (Fig. 3E).

We also examined the ability of these cells to form distant metastases in select organs. PC-3-CTRwt cells frequently formed micrometastases in multiple organs, including lymph nodes, femur and lungs (Fig. 3F, Tables 1, 2 , and 3). In contrast, $\mathrm{AKAP} 2_{\mathrm{KD}}$ cells did not form micrometastases in all tested organs except one out of six mice showed minor lymph node involvement. AKAP $\triangle$ PKA re-expressed cells also displayed a similar behavior. However, AKAP2-wt re-expressed cells formed metastases in several organs. H\&E sections of these tumors are presented in Figs S1-S2, see section on supplementary data given at the end of this article.

\section{Elevation of CTR and AKAP2 expression in primary prostate tumors}

Since the present results have identified an important role for AKAP2 in CTR-induced tumor growth and metastasis, we examined CTR and AKAP2 expression in paraffinembedded specimens of primary human prostate cancer. We selected a cohort of 83 prostate specimens consisting of $\mathrm{BPH}$, localized PC and metastatic PC. As shown in Fig. 4A, all BPH specimens displayed almost undetectable levels of AKAP2 $(n=16)$. In contrast, all PC specimens displayed visible-to-intense expression of AKAP2 $(n=67)$. When stratified the PC specimens into metastatic vs localized, the AKAP2 IHC index of metastatic PC specimens was significantly higher than localized PCs (Fig. 4B). CTR expression also followed a similar pattern (Fig. 4C and D). These results suggest that increased AKAP2 levels may facilitate the action of increased CTRs to promote PKA-mediated phosphorylation of key proteins, which are important for metastasis of PC.

Table 3 Micrometastases in host organs

\begin{tabular}{|c|c|c|c|c|}
\hline Organs & PC-3CTR & $\mathbf{A K A P}_{\mathrm{KD}}$ & AKAP $\triangle$ PKA & AKAP REEXP \\
\hline Seminal vesicles & +++ & - & - & +++ \\
\hline Lymph nodes & +++ & - & - & ++ \\
\hline Femur & +++ & - & - & ++ \\
\hline Lungs & ++ & - & - & + \\
\hline Liver & ++ & - & - & + \\
\hline Kidneys & ++ & - & - & + \\
\hline Brain & \pm & - & - & \pm \\
\hline
\end{tabular}

Published by Bioscientifica Ltd. 
A
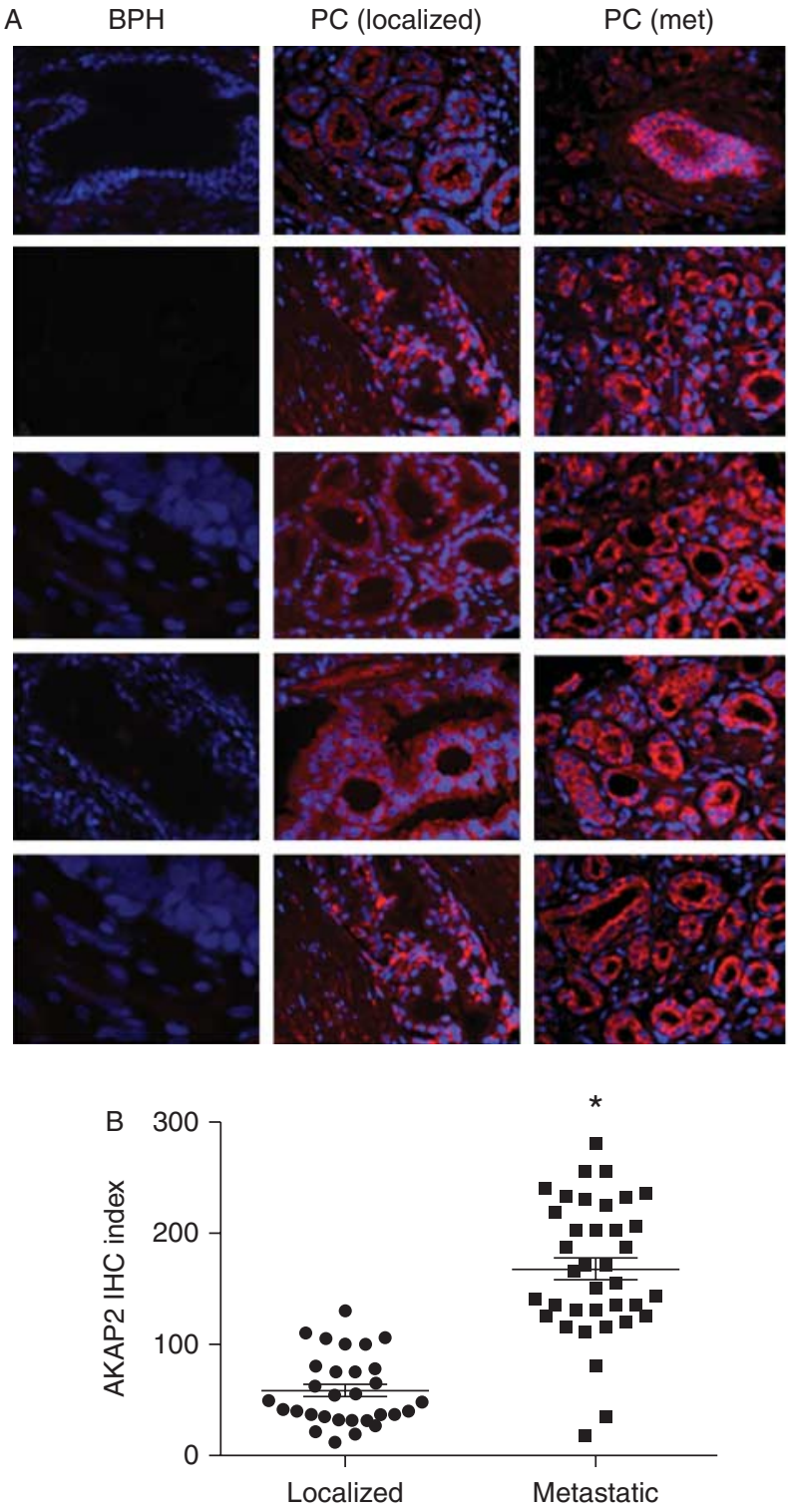

Figure 4

AKAP2 expression in human prostate tissues: immunofluorescence. (A) Representative micrographs of AKAP2 immunofluorescence in BPH, localized PC and metastatic PC. (B) AKAP2-positive cells/400 $\times$ field were counted as described in the methods section. The graph presents quantitative data (mean \pm S.E.M. for $n=37$ for localized PC and $n=30$ for

\section{Discussion}

Earlier studies from this laboratory have reported that CT is a potent stimulator of prostate cancer cell invasion (Thomas et al. 2006). However, specific, cell-permeable inhibitors of PKA almost abolish CT-induced invasion, suggesting that the pro-invasive actions of $\mathrm{CT}$ involve PKA-mediated mechanisms (Sabbisetti et al. 2005). Considering that PKA catalyzes several cellular processes such

$\begin{array}{lr}\text { http://erc.endocrinology-journals.org } & \text { (C) } 2016 \text { Society for Endocrinology } \\ \text { DOI: } 10.1530 / \text { ERC-15-0425 } & \text { Printed in Great Britain }\end{array}$

C
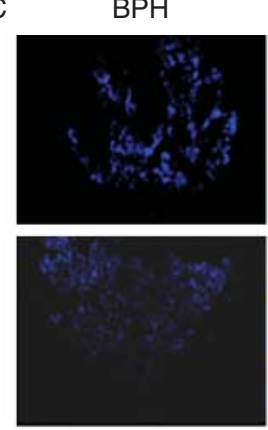

PC (localized)
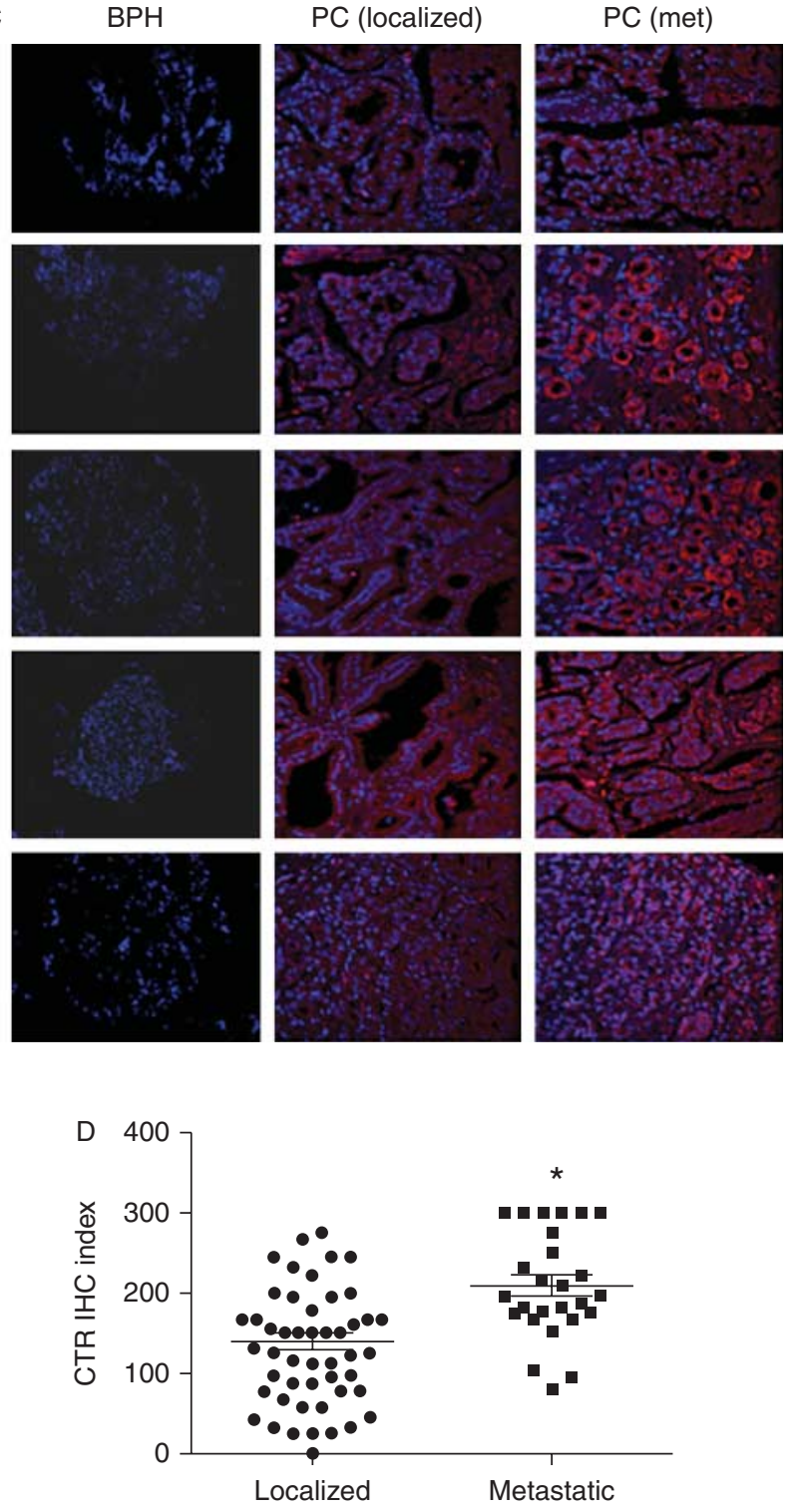

metastatic PC; ${ }^{*}<0.001$, paired $t$-test). (C) Representative micrographs of CTR immunofluorescence in BPH, localized PC and metastatic PC. (D) CTRpositive cells $/ 400 \times$ field were counted as described in the methods section. The graph presents quantitative data (mean \pm S.E.M. for $n=37$ for localized PC and $n=30$ for metastatic PC; ${ }^{*} P<0.001$, paired $t$-test).

as metabolism, gene transcription, ion channel conductivity, cell growth, cell division and rearrangement of the actin cytoskeleton (Carr et al. 1991, Francis \& Corbin 1994, Carr et al. 2001), it is now accepted that the specificity of PKA action to a stimulus is provided by spatial mechanisms involving adaptor proteins such as AKAPs that target PKA towards particular substrates (Carnegie \& Scott 2003, Wong \& Scott 2004, Lynch et al. 2005). AKAPs also recruit

Published by Bioscientifica Ltd. 
other signaling molecules to form localized signaling hubs (Wong \& Scott 2004, Lynch et al. 2005). Present results have used multiple experimental approaches to demonstrate that AKAP2 is expressed in human prostate, and it plays a key role in mediating the actions of CTR, and possibly other receptors, in stimulating tumor growth and metastasis. Specifically, the results that AKAP2 silencing remarkably reduced tumorigenicity and metastatic capacity of PC cells; and the re-expression of AKAP2-wt, but not AKAP2- $\triangle \mathrm{PKA}$, restored their tumorigenic and metastatic capacity demonstrate that AKAP2-tethered PKA is crucial for CTR-stimulated prostate cancer growth and metastasis (Fig. 5). Interestingly, this is the first known demonstration of the presence of AKAP2 in human prostate, and its role in PC progression.

The results of immunofluorescence revealed that AKAP2 was co-localized predominantly with ZO-1 but not as much with E-cadherin. Moreover, ZO-1 as well as AKAP2 co-precipitated with CTR, suggesting that the interaction among these three proteins may be important for CTR-induced invasion. The results raise several interesting possibilities. For example, ZO-1, besides being the marker of tight junctions, is an important scaffolding protein with multiple interacting domains including three PDZs, a SH3, a guanylate kinase (GK), actin binding region, and a ZU5 (ZO-1 and Unc5-like netrin receptor domain) (Fanning et al. 2002). ZO-1 acts as a key organizer of tight junctions (TJs) at the plasma membrane (Li et al.
2005). Based on co-localization and co-precipitation evidence, it appears that ZO-1 brings CTR into close proximity of AKAP2, where CTR can quickly and selectively activate this pool of PKA. Thus, AKAP2 may ensure that the PKA will phosphorylate proteins of junctional complexes. These results can explain multiple actions of CTR such as destabilization of cell-cell junctions, loss of cell adhesion, increase in invasion and the induction of EMT (Shah et al. 2009b). The cascade that follows this event may include loss of epithelial integrity, loss of cell polarity, increase in invasion, proliferation and activation of survival pathways that attenuate apoptosis and anoikis (Fig. 6). Further identification and functional characterization of AKAP2 - ZO-1 scaffold and its interaction with CTR will be critically important in revealing CTR-activated events associated with PC progression.

If AKAP2 plays an important role in prostate tumor growth/metastasis, one would expect its upregulation in aggressive prostate cancer. Although its expression in PC was not individually studied, available transcriptome profiling of human prostate cancer specimens suggested an upregulation of AKAP2 gene transcription in metastatic prostate cancer (Lapointe et al. 2004). However, there is no evidence for its physiological function or its role in prostate cancer pathogenesis. Therefore, we examined AKAP2 protein expression along with that of CTR in a cohort of human prostate cancer specimens.
A

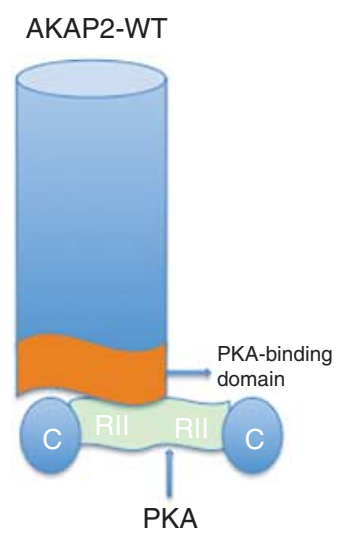

PKA binds to PKA-binding domain on AKAP2
B

AKAP2 $\triangle \mathrm{PKA}$

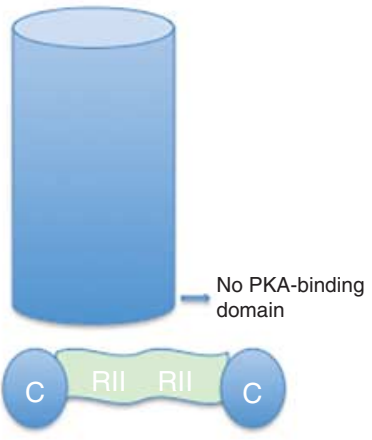

PKA cannot bind to AKAP2 because PKA-binding domain is deleted
C

AKAP2+Ht-32

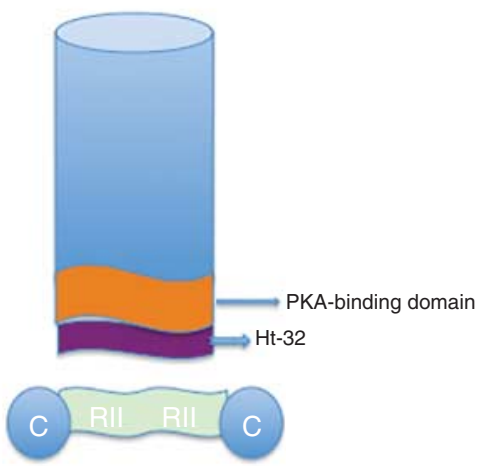

PKA cannot bind to AKAP2 because $\mathrm{Ht}-32$ has higher affinity for PKA-binding domain than PKA

Figure 5

Schematic diagram depicting the AKAP2, its PKA-binding domain and the impact of deletion of PKA-binding domain or st-Ht-31 action on the functionality of AKAP2. 
A

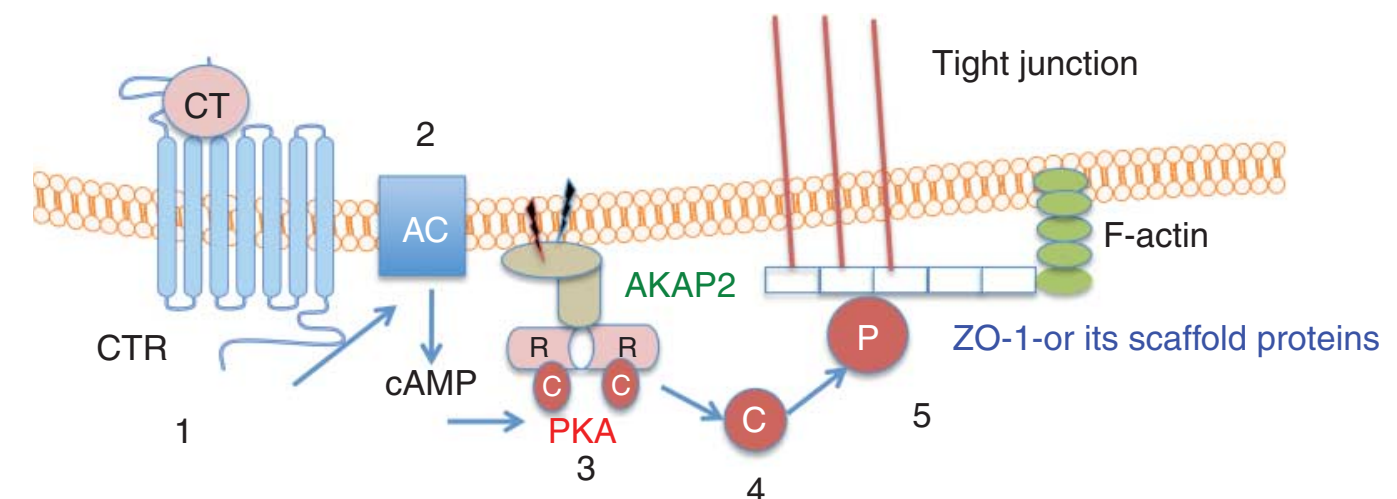

B

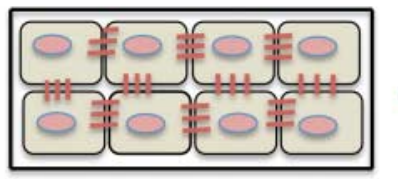

Organized epithelial structure with intact cell-cell junctions

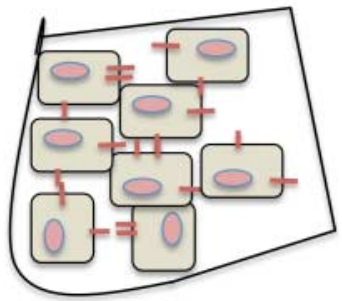

Loss of epithelial integrity<smiles>C1CC2CCC1C2</smiles>

Loss of cell polarity Increased cell proliferation Increased invasion Increased survival

\section{Figure 6}

Schematic diagram depicting mechanism of CTR action that involves AKAP2 and leads to EMT, increased invasion and tumor growth.

Present results - that both CTR and AKAP2 were very low in benign prostates but were very strong in metastatic prostate cancers - reinforce the association between CTR, AKAP2 and aggressive form of PC. Indeed, a detailed study with a larger cohort will be necessary to investigate the usefulness of AKAP2 as a prognostic indicator for metastatic form of PC.

In conclusion, present results have identified new molecular mechanisms associated with CTR-activated PC progression and metastasis. First, CT-activated pro-invasive actions require AKAP2, a novel finding. Co-localization of AKAP2 with ZO-1 suggests that the PKA tethered to AKAP2 is activated by CTR, and may phosphorylate ZO-1 or its scaffold proteins. This may lead to destabilization of cell-cell junctions, and lead to the loss of epithelial integrity and loss of cell polarity, eventually resulting in EMT and increased invasion (Fig. 6). Upregulation of
AKAP2 in metastatic prostate cancer and its importance in tumor growth/metastasis suggest that AKAP2 may serve as a prognostic indicator of cancer progression and as a new target for molecular therapy of advanced prostate cancer.

\section{Supplementary data}

This is linked to the online version of the paper at http://dx.doi.org/10.1530/ ERC-15-0425.

\section{Declaration of interest}

The authors declare that there is no conflict of interest that could be perceived as prejudicing the impartiality of the research reported.

\section{Funding}

This work was supported by grant CA096534 of National Institutes of Health to GVS.

Published by Bioscientifica Ltd. 


\section{References}

Beebe SJ 1994 The cAMP-dependent protein kinases and cAMP signal transduction. Seminars in Cancer Biology 5 285-294.

Carnegie GK \& Scott JD 2003 A-kinase anchoring proteins and neuronal signaling mechanisms. Genes and Development 17 1557-1568. (doi:10.1101/gad.1095803)

Carr DW, Stofko-Hahn RE, Fraser ID, Bishop SM, Acott TS, Brennan RG \& Scott JD 1991 Interaction of the regulatory subunit (RII) of cAMPdependent protein kinase with RII-anchoring proteins occurs through an amphipathic helix binding motif. Journal of Biological Chemistry $\mathbf{2 6 6}$ 14188-14192.

Carr DW, Fujita A, Stentz CL, Liberty GA, Olson GE \& Narumiya S 2001 Identification of sperm-specific proteins that interact with A-kinase anchoring proteins in a manner similar to the type II regulatory subunit of PKA. Journal of Biological Chemistry 276 17332-17338. (doi:10.1074/ jbc.M011252200)

Cereijido M, Gonzalez-Mariscal L, Contreras RG, Gallardo JM, Garcia-Villegas R \& Valdes J 1993 The making of a tight junction. Journal of Cell Science. Supplement 17 127-132. (doi:10.1242/jcs.1993. Supplement_17.18)

Chien J, Wong E, Nikes E, Noble MJ, Pantazis CG \& Shah GV 1999 Constitutive activation of stimulatory guanine nucleotide binding protein $(\mathrm{G}(\mathrm{S}) \alpha \mathrm{QL})$-mediated signaling increases invasiveness and tumorigenicity of PC-3M prostate cancer cells. Oncogene 18 3376-3382. (doi:10.1038/sj.onc.1202690)

Chien J, Ren Y, Qing Wang Y, Bordelon W, Thompson E, Davis R, Rayford W \& Shah G 2001 Calcitonin is a prostate epithelium-derived growth stimulatory peptide. Molecular and Cellular Endocrinology 181 69-79. (doi:10.1016/S0303-7207(01)00530-5)

Colledge M \& Scott JD 1999 AKAPs: from structure to function. Trends in Cell Biology 9 216-221. (doi:10.1016/S0962-8924(99)01558-5)

Dong F, Feldmesser M, Casadevall A \& Rubin CS 1998 Molecular characterization of a cDNA that encodes six isoforms of a novel murine A kinase anchor protein. Journal of Biological Chemistry 273 6533-6541. (doi:10.1074/jbc.273.11.6533)

Ebnet K 2008 Organization of multiprotein complexes at cell-cell junctions. Histochemistry and Cell Biology 130 1-20. (doi:10.1007/ s00418-008-0418-7)

Fanning AS, Ma TY \& Anderson JM 2002 Isolation and functional characterization of the actin binding region in the tight junction protein ZO-1. FASEB Journal 16 1835-1837. (doi:10.1096/fj.02-0121fje)

Force T, Bonventre JV, Flannery MR, Gorn AH, Yamin M \& Goldring SR 1992 A cloned porcine renal calcitonin receptor couples to adenylyl cyclase and phospholipase C. American Journal of Physiology $\mathbf{2 6 2}$ F1110-F1115.

Francis SH \& Corbin JD 1994 Structure and function of cyclic nucleotidedependent protein kinases. Annual Review of Physiology 56 237-272. (doi:10.1146/annurev.ph.56.030194.001321)

Gold MG, Lygren B, Dokurno P, Hoshi N, McConnachie G, Tasken K, Carlson CR, Scott JD \& Barford D 2006 Molecular basis of AKAP specificity for PKA regulatory subunits. Molecular Cell 24 383-395. (doi:10.1016/j.molcel.2006.09.006)

Gold MG, Reichow SL, O'Neill SE, Weisbrod CR, Langeberg LK, Bruce JE, Gonen T \& Scott JD 2012 AKAP2 anchors PKA with aquaporin-0 to support ocular lens transparency. EMBO Molecular Medicine 4 15-26. (doi:10.1002/emmm.201100184)

Jackel MC, Mitteldorf C, Schweyer S \& Fuzesi L 2001 Clinical relevance of Fas (APO-1/CD95) expression in laryngeal squamous cell carcinoma. Head \& Neck 23 646-652. (doi:10.1002/hed.1091)

Jarnaess E, Ruppelt A, Stokka AJ, Lygren B, Scott JD \& Tasken K 2008 Dual specificity A-kinase anchoring proteins (AKAPs) contain an additional binding region that enhances targeting of protein kinase A type I. Journal of Biological Chemistry 283 33708-33718. (doi:10.1074/jbc. M804807200)
Lapointe J, Li C, Higgins JP, van de Rijn M, Bair E, Montgomery K, Ferrari M, Egevad L, Rayford W, Bergerheim U et al. 2004 Gene expression profiling identifies clinically relevant subtypes of prostate cancer. PNAS 101 811-816. (doi:10.1073/pnas.0304146101)

Leve F, de Souza W \& Morgado-Diaz JA 2008 A cross-link between protein kinase A and Rho-family GTPases signaling mediates cell-cell adhesion and actin cytoskeleton organization in epithelial cancer cells. Journal of Pharmacology and Experimental Therapeutics 327 777-788. (doi:10.1124/ jpet.108.140798)

Lewis JE, Jensen PJ, Johnson KR \& Wheelock MJ 1994 E-cadherin mediates adherens junction organization through protein kinase C. Journal of Cell Science 107 (Pt 12) 3615-3621.

Li Y, Fanning AS, Anderson JM \& Lavie A 2005 Structure of the conserved cytoplasmic C-terminal domain of occludin: identification of the ZO-1 binding surface. Journal of Molecular Biology 352 151-164. (doi:10.1016/ j.jmb.2005.07.017)

Lynch MJ, Baillie GS, Mohamed A, Li X, Maisonneuve C, Klussmann E, van Heeke G \& Houslay MD 2005 RNA silencing identifies PDE4D5 as the functionally relevant cAMP phosphodiesterase interacting with $\beta$ arrestin to control the protein kinase A/AKAP79-mediated switching of the $\beta 2$-adrenergic receptor to activation of ERK in HEK293B2 cells. Journal of Biological Chemistry 280 33178-33189. (doi:10.1074/jbc. M414316200)

McConnachie G, Langeberg LK \& Scott JD 2006 AKAP signaling complexes: getting to the heart of the matter. Trends in Molecular Medicine 12 317-323. (doi:10.1016/j.molmed.2006.05.008)

Offermanns S, Iida-Klein A, Segre GV \& Simon MI 1996 G $\propto$ q family members couple parathyroid hormone (PTH)/PTH-related peptide and calcitonin receptors to phospholipase C in COS-7 cells. Molecular Endocrinology 10 566-574. (doi:10.1210/me.10.5.566)

Parthier C, Reedtz-Runge S, Rudolph R \& Stubbs MT 2009 Passing the baton in class B GPCRs: peptide hormone activation via helix induction? Trends in Biochemical Sciences 34 303-310. (doi:10.1016/j.tibs.2009.02.004)

Rajasekaran SA, Gopal J, Espineda C, Ryazantsev S, Schneeberger EE \& Rajasekaran AK 2004 HPAF-II, a cell culture model to study pancreatic epithelial cell structure and function. Pancreas 29 e77-e83. (doi:10.1097/00006676-200410000-00016)

Sabbisetti VS, Chirugupati S, Thomas S, Vaidya KS, Reardon D, ChirivaInternati M, Iczkowski KA \& Shah GV 2005 Calcitonin increases invasiveness of prostate cancer cells: role for cyclic AMP-dependent protein kinase A in calcitonin action. International Journal of Cancer $\mathbf{1 1 7}$ 551-560. (doi:10.1002/ijc.21158)

Shah GV, Rayford W, Noble MJ, Austenfeld M, Weigel J, Vamos S \& Mebust WK 1994 Calcitonin stimulates growth of human prostate cancer cells through receptor-mediated increase in cyclic adenosine $3^{\prime}, 5^{\prime}$-monophosphates and cytoplasmic $\mathrm{Ca}^{2+}$ transients. Endocrinology 134 596-602. (doi:10.1210/endo.134.2.8299557)

Shah GV, Thomas S, Muralidharan A, Liu Y, Hermonat PL, Williams J \& Chaudhary J 2008 Calcitonin promotes in vivo metastasis of prostate cancer cells by altering cell signaling, adhesion, and inflammatory pathways. Endocrine-Related Cancer 15 953-964. (doi:10.1677/ ERC-08-0136)

Shah GV, Muralidharan A, Thomas S, Gokulgandhi M, Mudit M, Khanfar M \& El Sayed K 2009a Identification of a small molecule class to enhance cell-cell adhesion and attenuate prostate tumor growth and metastasis. Molecular Cancer Therapeutics 8 509-520. (doi:10.1158/1535-7163.MCT08-0693)

Shah GV, Muralidharan A, Gokulgandhi M, Soan K \& Thomas S 2009b Cadherin switching and activation of $\beta$-catenin signaling underlie proinvasive actions of calcitonin-calcitonin receptor axis in prostate cancer. Journal of Biological Chemistry 284 1018-1030. (doi:10.1074/jbc. M807823200)

Stratakis CA \& Cho-Chung YS 2002 Protein kinase A and human disease. Trends in Endocrinology and Metabolism 13 50-52. (doi:10.1016/S10432760(01)00560-4) 
Theurkauf WE \& Vallee RB 1982 Molecular characterization of the cAMPdependent protein kinase bound to microtubule-associated protein 2 . Journal of Biological Chemistry 257 3284-3290.

Thomas S, Chigurupati S, Anbalagan M \& Shah G 2006 Calcitonin increases tumorigenicity of prostate cancer cells: evidence for the role of protein kinase A and urokinase-type plasminogen receptor. Molecular Endocrinology 20 1894-1911. (doi:10.1210/me.2005-0284)

Thomas S, Chiriva-Internati M \& Shah GV 2007 Calcitonin receptorstimulated migration of prostate cancer cells is mediated by urokinase receptor-integrin signaling. Clinical \& Experimental Metastasis 24 363-377. (doi:10.1007/s10585-007-9073-y)

Vijayaraghavan S, Goueli SA, Davey MP \& Carr DW 1997 Protein kinase A-anchoring inhibitor peptides arrest mammalian sperm motility.
Journal of Biological Chemistry 272 4747-4752. (doi:10.1074/jbc.272.8. 4747)

von Zastrow M \& Kobilka BK 1994 Antagonist-dependent and -independent steps in the mechanism of adrenergic receptor internalization. Journal of Biological Chemistry 269 18448-18452.

Wong W \& Scott JD 2004 AKAP signalling complexes: focal points in space and time. Nature Reviews. Molecular Cell Biology 5 959-970. (doi:10.1038/nrm1527)

Wookey P 2009 A review of calcitonin receptor expression in embryonic, foetal and adult tissues, with an hypothesis on the connection between expression during foetal development and disease. Open Zoology Journal 2 53-61. (doi:10.2174/ 1874336600902010053)

Received in final form 25 September 2015

Accepted 2 October 2015

Made available online as an Accepted Preprint

2 October 2015
Published by Bioscientifica Ltd. 